\title{
CONTRIBUIÇÕES TEÓRICAS DE MARCUSE SOBRE AS NOVAS FORMAS DE CONTROLE E DOMINAÇÃO NAS SOCIEDADES CAPITALISTAS
}

\author{
Paulo Sérgio Gomes Soares ${ }^{1}$ \\ Rafael Silva Oliveira ${ }^{2}$
}

\begin{abstract}
Resumo:
A luta pela permanência e estabilidade do capital está sendo travada na esfera cultural pela exploração da subjetividade dos indivíduos e daquilo que os faz ser o que são: a consciência. A partir da análise da Teoria Crítica da Sociedade do filósofo Herbert Marcuse, o artigo apresenta um debate que gira em torno das formas de controle social emergentes nas sociedades capitalistas, que estão voltadas para dominar os indivíduos pela satisfação das necessidades superimpostas e, contraditoriamente, movimentar as engrenagens do sistema. Investiga-se em que medida a técnica e a tecnologia contribuem para instituir as novas formas de controle social a partir do conceito de racionalidade tecnológica. O objetivo é apontar as contradições da razão em meio ao ambiente tecnológico, envolvendo a relação entre indivíduo e sociedade a partir da introjeção da cultura do consumo para a administração total da vida. A luta pela existência frente ao aparato de produção e consumo que impõe um padrão de vida crescente sofre a pressão do mundo administrado por forças estranhas ao controle dos indivíduos, comprometendo a sua emancipação por eliminar a crítica e impedir o livre desenvolvimento de suas faculdades. O debate mostra que as sociedades capitalistas reprimem, precondicionam e introjetam as falsas necessidades, minando as possibilidades reais de transformação qualitativa da sociedade.
\end{abstract}

Palavras-chave: Teoria Crítica. Racionalidade Tecnológica. Controle Social. Capitalismo. Cultura do Consumo.

\section{THEORETICAL CONTRIBUTIONS OF MARCUSE ON THE NEW FORMS OF CONTROL AND DOMINATION IN CAPITALIST COMPANIES}

\begin{abstract}
:
The struggle for permanence and stability of capital is being waged in the cultural sphere by the exploration of the subjectivity of individuals and of what makes them what they are: consciousness. From the analysis of the Critical Theory of Society of the philosopher Herbert Marcuse, the article presents a debate that revolves around the emerging forms of social control in capitalist societies, which are aimed at dominating individuals by satisfying superimposed needs and, contradictorily, moving the gears of the system. It is investigated to what extent technology and technology contribute to instituting the new forms of social control from the concept of technological rationality. The objective is to point out the contradictions of reason in the midst of the technological environment, involving the relationship between individual and society from the introjection of the culture of consumption to the total administration of life. The struggle for existence in the face of the apparatus of production and consumption which imposes a growing standard of living undergoes the pressure of the world administered by forces alien to the control of individuals, compromising their emancipation by eliminating criticism and impeding the free development of their faculties. The debate shows that capitalist societies repress, precondition and introject false needs, undermining the real possibilities of qualitative transformation of society.
\end{abstract}

Keywords: Critical Theory. Technological Rationality. Social Control. Capitalism. Culture of Consumption.

\footnotetext{
${ }^{1}$ Doutor em Educação (UFSCar/2012). Mestre em Epistemologia, Lógica e Filosofia da Ciência (UNESP/2004). Licenciado em Filosofia (UNESP/1997). Professor do Mestrado Profissional em Filosofia (PROF-FILO/UFT) e no Programa de Pós-Graduação Interdisciplinar em Prestação Jurisdicional e Direitos Humanos (UFT/ESMAT). E-mail: psoares@uft.edu.br.

2 Mestre em Filosofia (UFT/2019), especialista em Ética e Ensino de Filosofia na Educação Básica (UFT/2016). Licenciado em Filosofia (UFT/2014). Professor do Instituto Tocantinense de Pós-Graduação (ITOP). E-mail: rafael.siloli@gmail.com.
} 


\section{Introdução}

Atualmente, retomar o pensamento do filósofo frankfurtiano Herbert Marcuse (18981979) se faz necessário para compreender as contradições produzidas pelas sociedades capitalistas em seu atual estágio de desenvolvimento tecnológico. O pressuposto fundamental é que a luta pela permanência e estabilidade do capital não está sendo travada somente nas esferas política e econômica, mas, sobretudo, na esfera cultural pela exploração da subjetividade dos indivíduos e daquilo que os faz ser o que são: a consciência.

Essa pesquisa teórica fundamentada na Teoria Crítica procurou compreender a transformação da racionalidade individualista em racionalidade tecnológica e da racionalidade tecnológica em racionalidade política para assumir a administração total da vida dos indivíduos a partir da luta pela existência. A introjeção da racionalidade tecnológica ajustou os indivíduos aos precondicionamentos sociais e contribuiu para transformar os instintos, os desejos e os pensamentos humanos em atitudes desejáveis para a reprodução do sistema capitalista. $\mathrm{O}$ fenômeno da introjeção da cultura do consumo e os seus efeitos nas relações sociais se constituem em pressupostos para analisar a dinâmica e o desenvolvimento das sociedades capitalistas, avaliando como estão sendo utilizados os recursos naturais e intelectuais no curso do processo civilizatório.

A racionalidade tecnológica se transforma em racionalidade política quando o projeto do capitalismo antevê maneiras de utilizar a natureza e os indivíduos para se reproduzir. Nesse sentido, de um ponto de vista político, a técnica e a tecnologia são fundamentais para o controle da natureza e para conquistar e dominar os indivíduos cientificamente. Portanto, elas não podem ser vistas como neutras.

A hipótese investigada é de que nas sociedades capitalistas tendem a prevalecer o autoritarismo e a escassez, bem como o aumento do trabalho árduo, porque sempre novas formas de controle são criadas em estreita relação com a formação de uma racionalidade - a racionalidade tecnológica -, que é uma racionalidade técnica formada pelos padrões da máquina (tecnologia) para consolidar formas específicas de controle, dominação e submissão dos indivíduos a maneiras alienadas de vida, que vêm sendo introjetadas desde o advento da Revolução Industrial até os dias atuais com a revolução tecnológica digital.

O objetivo do artigo é expressar as tensões e contradições da razão em meio a um ambiente tecnológico que exige a submissão dos indivíduos aos interesses de um sistema que obstaculiza a libertação da consciência e, portanto, o processo de emancipação humana rumo

\begin{tabular}{|c|c|c|c|c|}
\cline { 2 - 5 } Q Dovista & Ano 8 & n. 14 & Janeiro - Julho 2019 & p. $91-109$ \\
\hline
\end{tabular}




\section{CONTRIBUICÕES TEÓRICAS DE MARCUSE SOBRE AS NOVAS...}

Paulo Sérgio Gomes Soares / Rafael Silva Oliveira

ao reino da liberdade. A ideia é desvelar como se efetiva a dominação dos indivíduos pela satisfação no consumo das falsas necessidades.

A ideologia das sociedades capitalistas se assenta na falsa consciência consolidada na troca da liberdade pelo conforto, ou seja, no consumo de necessidades superimpostas que cobram em troca o conformismo. A lógica da dominação social se fundamenta em um processo de produção e consumo que destrói as possibilidades reais de amenizar a luta pela existência.

O consumo alienado de necessidades superimpostas é um requisito básico para constituição e efetivação das diferentes formas de controle dos indivíduos nas sociedades capitalistas e este artigo mostra como elas produzem uma falta de liberdade confortável e democrática no atual estágio de desenvolvimento das forças produtivas. As necessidades superimpostas são compreendidas como falsas necessidades que impedem o livre desenvolvimento das faculdades humanas e a emancipação dos indivíduos.

Ao se submeterem ao sistema de produção e consumo e serem ajustados à racionalidade tecnológica, os indivíduos alimentam os meios de destruição de sua própria liberdade, tornandose dependentes dos preceitos que a sociedade impõe para se manterem inseridos nela. Enfim, constatou-se com base na análise da Teoria Crítica marcuseana que as falsas necessidades são as novas formas de controle social e, portanto, representam um sério problema para o processo, necessário e urgente, de emancipação humana.

A Teoria Crítica da Sociedade de Marcuse evidencia as contradições do nosso tempo histórico e procura desvelar alternativas que representem possibilidades reais de transformação do sistema vigente a partir da crítica. Em tese, a restituição da razão crítica pode viabilizar a negação para uma possível superação, no sentido de elevação, dessa sociedade, possibilitando o surgimento de outras alternativas históricas de florescimento social e novas formas de existência humana.

As perguntas que nortearam a investigação são as seguintes: atualmente, as sociedades capitalistas estão fazendo uso otimizado dos recursos naturais e intelectuais para minimizar a labuta pela existência? O atual estágio de desenvolvimento das forças produtivas permite dizer que o processo civilizatório, propugnado pelo capital, conduz a emancipação?

\section{A racionalidade tecnológica e a reprodução do capital}

\begin{tabular}{|l|l|l|l|l|}
\hline Govista 2 Dialectus & Ano 8 & n. 14 & Janeiro - Julho 2019 & p. $91-109$ \\
\hline
\end{tabular}


Em artigo intitulado Algumas implicações sociais da tecnologia moderna ${ }^{3}$, Marcuse (1999, p. 74) afirma que "a técnica por si só pode promover tanto o autoritarismo quanto a liberdade, tanto a escassez quanto a abundância, tanto o aumento quanto a abolição do trabalho árduo".

Constata-se que no processo de desenvolvimento tecnológico, uma nova racionalidade e novos padrões de individualidade se disseminaram na sociedade, modificando a concepção de indivíduo forjado pelo liberalismo no século XVIII, que "tinha de superar todo o sistema de ideias e valores que lhe era imposto, para encontrar e apossar-se de ideias e valores que se ajustassem a seu interesse racional" (MARCUSE, 1999, p. 75). Esse indivíduo que nenhuma autoridade externa deveria desrespeitar foi afetado pelo aparato da sociedade industrial, transformando a racionalidade individualista em racionalidade tecnológica. Esta última estabeleceu padrões de comportamento e julgamento que predispuseram os indivíduos a introjetar os ditames do sistema de produção e consumo, ou seja, a aceitarem os padrões e os valores externos da ordem social vigente.

Cabe, nesse primeiro momento, compreender a ideologia da sociedade industrial e como a racionalidade individualista foi transformada em racionalidade tecnológica para assumir a administração da vida dos indivíduos a partir da própria luta pela existência. Este artigo busca compreender esse fenômeno, partindo do pressuposto de que "ao manipular a máquina, o homem aprende que a obediência às instruções é o único meio de se obter resultados desejados. Ser bem-sucedido é o mesmo que adaptar-se ao aparato. Não há lugar para a autonomia" (MARCUSE, 1999, p. 80). A adaptação e a submissão razoável são características de uma racionalidade tecnológica objetivada em atitude desejável e todo esse processo contribuiu para transformar os instintos, os desejos e pensamentos humanos em canais que alimentam o aparato. “Os homens não vivem sua própria vida, mas desempenham tão-só funções preestabelecidas. Enquanto trabalham, não satisfazem suas próprias necessidades e faculdades, mas trabalham em alienação" (MARCUSE, 1975, p. 58).

Como, quando e porque os indivíduos começaram a apresentar padrões de reação confiáveis, comportamentos mecânicos, hábitos emocionais fixos e insensibilidade à perda da liberdade? Uma possível resposta, dentre outras, é que as organizações sociais capitalistas não

3 Segundo Kellner (1999), neste artigo publicado em inglês na revista do Instituto de Pesquisa Social, em 1941, contém o primeiro esboço de Marcuse sobre o papel da tecnologia nas sociedades industriais e antecipa sua análise sobre a temática, presente no livro intitulado A ideologia da sociedade industrial, que foi publicado originalmente em 1964 com o título One-Dimensional Man: Studies in the Ideology of Advanced Industrial Society. Utilizamos na escrita uma versão em português de 1973.

\begin{tabular}{|c|c|c|c|c|}
\hline Rovista Dialectus & Ano 8 & n. 14 & Janeiro - Julho 2019 & p. $91-109$ \\
\hline
\end{tabular}


mantêm o poder por meio da força, mas pela identificação dos indivíduos com o aparato. As formas de controle social são tecnológicas e se apresentam como a própria personificação da razão, representando o "bem" para todas as classes e interesses sociais. São formas de controle históricas de precondicionamento que caminham juntas com o desenvolvimento das forças produtivas.

Assim,

a máquina adorada não é mais matéria morta, mas se torna algo semelhante a um ser humano. E devolve ao homem o que ela possui: a vida do aparato social ao qual pertence. $\mathrm{O}$ comportamento humano se reveste da racionalidade do processo da máquina, e esta racionalidade tem um conteúdo social definido (MARCUSE, 1999, p. 81).

Pelo excerto fica evidente que tanto a técnica quanto a tecnologia não são neutros, pelo contrário, justificaram a ideologia da sociedade industrial. A tecnologia é concebida como um processo social no qual a técnica propriamente dita (isto é, o aparato técnico da indústria, transportes, comunicação) não passa de um fator parcial. A tecnologia, por sua vez, é "uma forma de organizar e perpetuar (ou modificar) as relações sociais, uma manifestação do pensamento e dos padrões de comportamento dominantes, um instrumento de controle e dominação" (MARCUSE, 1999, p. 73-74).

Trata-se de um instrumento de controle e dominação que criou um novo padrão de individualidade e se disseminou na sociedade como produto do desenvolvimento tecnológico e da produção em massa, avançando até os dias atuais, isto é, até o atual estágio de desenvolvimento das forças produtivas e do próprio capital, agora financeirizado. Hoje, a relação entre os indivíduos é mediada pelas tecnologias, a ponto de se identificarem de forma acrítica com o sistema. Todavia,

os equipamentos mecânicos que facilitam o contato entre os indivíduos também interceptam e absorvem sua libido, desta forma distanciando-o do reino por demais perigoso no qual o indivíduo se encontra livre da sociedade. O homem médio dificilmente se importa com outro ser vivo com a intensidade e persistência que demonstra por seu automóvel (MARCUSE, 1999, p. 81).

Ao se identificarem com o modo de existência que lhes foi imposto, diz-se que os indivíduos introjetaram a racionalidade tecnológica e que a identificação com as mercadorias tem representado, desde então, a troca da liberdade pelo conforto e, por conseguinte, o individualismo no sentido mais perverso que se possa imaginar. Com base no pensamento freudiano, Marcuse (1973, p 30) afirma que a "introjeção sugere uma variedade de processos relativamente espontâneos pelos quais um Eu (Ego) transfere o 'exterior' para o 'interior'”.

\begin{tabular}{|c|c|c|c|c|}
\cline { 2 - 5 } Q Dovista & Ano 8 & n. 14 & Janeiro - Julho 2019 & p. $91-109$ \\
\hline
\end{tabular}


Dessa forma, a autonomia da razão perde o seu sentido ao ser moldada pelas exigências técnicas do aparato que ela mesma criou. Quanto mais os indivíduos se comportam racionalmente conforme esse modelo de racionalidade -, tanto mais sucumbem aos aspectos frustrantes da cultura do consumo. A condição de irracionalidade a que os indivíduos foram reduzidos, contraditoriamente, tornou-se a base de sua sobrevivência. "Defrontamos novamente com um dos aspectos mais perturbadores da civilização industrial desenvolvida: o caráter racional de sua irracionalidade" (MARCUSE, 1973, p. 29).

Freud (1996) mostrou que o superego do homem é um aparato repressor interno e se apresenta como vantagem cultural preciosa, pois é por ele que os valores socioculturais são internalizados evitando medidas externas de coerção. Esse pressuposto, por um lado, serve ao processo civilizatório, pois retira o homem da condição de natureza e o coloca na condição cultural. A repressão transforma os indivíduos. Por outro lado, pode fazer com que os indivíduos introjetem a cultura dominante, no caso, a cultura do consumo, garantindo a reprodução do sistema capitalista enquanto reproduzem a sua existência.

Salta aos olhos tamanha alteração da individualidade. A relação entre o exterior, que deveria ser antagônico, e o interior do indivíduo, que parece ter perdido esse caráter de liberdade. O espaço privado foi invadido e desbastado pela realidade tecnológica. Assim, a identificação imediata e automática com o aparato parece anular a dimensão interior da mente, essa dimensão que faz o indivíduo ser o que ele é. “A perda dessa dimensão, na qual o poder de pensamento negativo - o poder crítico da Razão - está à vontade, é a contrapartida ideológica do próprio processo material no qual a sociedade industrial desenvolvida silencia e reconcilia a oposição" (MARCUSE, 1973, p 31).

Evidentemente, as transformações ocorridas nas sociedades industriais provocaram mudanças na consciência e na ação política das classes que se confrontam historicamente na sociedade: a burguesia e o proletariado. A estrutura e a função dessas duas classes foram alteradas, de tal modo que elas não parecem mais ser agentes de transformação histórica. Os antigos antagonistas parecem ter objetivos comuns, a saber, defender um padrão de vida que legitima e perpetua o status quo.

Diante do caráter total das conquistas da sociedade industrial desenvolvida, a Teoria Crítica parece desprovida de fundamento lógico para transcender essa sociedade. As categorias e termos pertencentes a essa teoria, que outrora foram criados em um período no qual a necessidade de recusa e subversão estava personificada na ação de forças sociais eficazes, contemporaneamente, foram reduzidas a críticas previstas dentro do status quo dominante e

\begin{tabular}{|c|c|c|c|c|}
\cline { 2 - 4 } Govista Dialectus & Ano 8 & n. 14 & Janeiro - Julho 2019 & p. $91-109$ \\
\hline
\end{tabular}


operacionais dentro da lógica do capital. A consciência feliz não fomenta a crítica para além do já previsto pelo sistema (KELLNER, 2011).

Portanto, ambas as classes sociais sucumbem à mesma lógica de dominação social ao cederem a pressão da vida administrada pela conquista da consciência feliz. Na falta desses agentes de transformação, a crítica é recuada para um alto nível de abstração, mas ainda assim, o filósofo ressalta a importância da Teoria Crítica diante desse cenário, pois “[...] a análise crítica continua insistindo em que a necessidade de transformação qualitativa é tão premente quanto em qualquer época. Necessária a quem? A resposta continua sendo a mesma: à sociedade como um todo, para cada um de seus membros” (MARCUSE, 1973, p. 16).

$\mathrm{O}$ fato de ambas as classes sociais sucumbirem à lógica do sistema não significa que a luta de classes chegou ao fim, mas tão somente que os indivíduos introjetraram os valores da cultura afirmativa $^{4}$, transformando a livre consciência em consciência feliz, que á a expressão mais clara da falsa consciência. Nesse ponto, vale ressaltar que a falsa consciência é o que constitui, propriamente, a ideologia da sociedade industrial. O conceito de ideologia foi muito bem definido nesses termos por Chaui (2013, p. 117):

\begin{abstract}
A ideologia é um conjunto lógico, sistemático e coerente de representações (ideias e valores) e de normas ou regras (de conduta) que indicam e prescrevem aos membros de uma sociedade o que devem pensar, o que devem valorizar e como devem valorizar, e que devem sentir e como devem sentir, o que devem fazer e como devem fazer. Ela é, portanto, um conjunto de ideias ou representações com teor explicativo (ela pretende dizer o que é a realidade) e prático ou de caráter prescritivo, normativo, regulador, cuja função é dar aos membros de uma sociedade dividida em classes uma explicação racional para as diferenças sociais, políticas e culturais, sem jamais atribuílas à divisão da sociedade em classes, determinada pelas divisões na esfera da produção econômica.
\end{abstract}

Vale ressaltar que a falsa consciência é o que constitui, propriamente, a ideologia nesse sentido apontado pela autora. Essa ideologia é a base para a transformação da racionalidade tecnológica em racionalidade política, como se vislumbra na seção seguinte.

\title{
2. A relação estreita entre a racionalidade política e as falsas necessidades
}

O padrão de vida crescente na sociedade capitalista, em seu atual estágio de desenvolvimento, sustém o controle da natureza e a dominação dos homens a partir do sistema

\footnotetext{
4 Marcuse desvenda a mecânica afirmativa da cultura como modo de garantir a subordinação do indivíduo ao universal dado, eternizando-o. Dizer que a cultura possui caráter afirmativo é questionar a sua negatividade, sua dimensão emancipatória (MAAR, 1997, p. 26).

\begin{tabular}{|l|c|c|c|c|}
\hline Qovista 2 ialectus & Ano 8 & n. 14 & Janeiro - Julho 2019 & p. $91-109$ \\
\hline
\end{tabular}
}


de produção e consumo. Esse modelo de organização social "antevê maneiras específicas de utilizar o homem e a natureza e rejeita outras maneiras", portanto, trata-se de um projeto de organização social entre outros, "mas, assim que o projeto se torna operante nas instituições e relações básicas, tende a tornar-se exclusivo e a determinar o desenvolvimento da sociedade em seu todo" (MARCUSE, 1973, p. 19).

A conquista da natureza levou à conquista dos indivíduos tecnologicamente. Marcuse deixa claro que a racionalidade tecnológica opera desde o seu conceito, politicamente. E esse caráter político é revelado quando ela "se torna o grande veículo de melhor dominação, criando um universo verdadeiramente totalitário no qual sociedade e natureza, corpo e mente são mantidos num estado de permanente mobilização para a defesa desse universo" (MARCUSE, 1973, p. 37). A dominação tecnológica possui um suporte político.

Por rejeitar outras maneiras de utilização dos recursos materiais e intelectuais, senão a transformação da natureza como mero material de controle e dos indivíduos como mera força de trabalho disponível para a dominação, Marcuse (1973, p. 19) entende que as sociedades capitalistas são totalitárias e unidimensionais, porque moldam "todo universo da palavra e da ação, a cultura intelectual e material. [...] No ambiente tecnológico, a cultura, a política e a economia se fundem num sistema onipresente que engolfa ou rejeita todas as alternativas". Em resumo, são totalitárias porque invadem todas as esferas da vida e unidimensionais porque impedem o florescimento de outras alternativas históricas de organização social diferentes da vigente.

A contradição é negada pela unidimensionalidade dessa sociedade, aspecto esse que foi resultado da eficiência e do poder da sociedade tecnológica/industrial que oprimiu o indivíduo a ponto dele perder os traços característicos da racionalidade crítica - autonomia, discordância, poder de negação, etc. (KELLNER, 1999). Os indivíduos foram presos numa única dimensão da realidade, surgindo assim o que Marcuse denominou de "homem unidimensional", que é subproduto de uma racionalidade e sociedade unidimensionais. Os indivíduos foram despidos de suas capacidades críticas pela racionalidade unidimensional sob a qual vivem e agora parecem renunciar à liberdade sob os ditames do aparato que introjetaram. O termo aparato designa as instituições, dispositivos e organizações da indústria que representam a ordem dominante.

Cabe ao aparato reduzir toda a potencialidade do pensamento crítico à unidimensionalidade e eliminar qualquer oposição eficaz ao todo. Sua função é reprimir, precondicionar e introjetar a falsa consciência. A forma como as sociedades capitalistas

\begin{tabular}{|c|c|c|c|c|}
\cline { 2 - 4 } Govista & Ano 8 & n. 14 & Janeiro - Julho 2019 & p. $91-109$ \\
\hline
\end{tabular}


organizam suas bases produtivas precisa ser totalitária e unidimensional, sem se configurar uma coordenação política terrorista, mas tão somente "uma coordenação técnico-econômica nãoterrorista que opera através da manipulação das necessidades por interesses adquiridos" (MARCUSE, 1973, p. 25).

O aparato técnico de produção e distribuição funciona como um sistema que determina, a priori, tanto o produto do aparato como as operações de sua manutenção e ampliação, ligadas a funções sociais e políticas específicas. Assim, a técnica e a tecnologia, materializadas nos produtos tecnológicos, desempenham um papel fundamentalmente político para a manutenção da ordem dominante e servem para instituir formas novas - eficazes e agradáveis - de controle e coesão social.

Os produtos doutrinam e manipulam; promovem uma falsa consciência que é imune à sua falsidade. E, ao ficarem esses produtos benéficos à disposição de maior número de indivíduos e de classes sociais, a doutrinação que eles portam deixa de ser publicidade; torna-se um estilo de vida. É um bom estilo de vida - muito melhor do que antes - e, como um bom estilo de vida, milita contra a transformação qualitativa (MARCUSE, 1973, p. 32).

As sociedades capitalistas são capazes de atender às necessidades dos indivíduos devido à forma como estão organizadas, voltadas para a produção e o consumo eficientes em meio à promessa de um padrão de vida crescente e de um estilo de vida conforme os padrões dominantes. A reprodução do sistema depende da repressão das possibilidades reais de transformação social. Para tanto, os precondicionamentos para a cultura do consumo se sobrepõem um após o outro de acordo com o próprio desenvolvimento histórico do capital.

Esse aspecto ideológico fica em silenciosa presença na mente dos indivíduos, dando a falsa sensação de uma plena consciência de que não há alternativa senão buscar por si mesmo concretizar um bom estilo de vida. O indivíduo se sente capaz, por meio do seu esforço e trabalho, de satisfazer todas as suas necessidades, quando, na verdade, não é ele que cria as suas necessidades, já que são necessidades superimpostas. Portanto, independe do quanto essas necessidades tenham sido próprias do indivíduo, o que importa é que foram reproduzidas e fortalecidas na luta pela existência e, mesmo que o indivíduo encontre satisfação em tais necessidades, estas continuam a ser produtos de uma sociedade cujo interesse dominante exige repressão.

Em última análise, a questão sobre quais necessidades devam ser falsas ou verdadeiras só pode ser respondida pelos próprios indivíduos, mas apenas em última análise; isto é, se e quando eles estiverem livres para dar a sua própria resposta. Enquanto eles forem mantidos incapazes de ser

\begin{tabular}{|c|c|c|c|c|}
\cline { 2 - 4 } Q Devistalectus & Ano 8 & n. 14 & Janeiro - Julho 2019 & p. 91 - 109 \\
\hline
\end{tabular}


autônomos, enquanto forem doutrinados e manipulados (até os seus próprios instintos) a resposta que derem a essa questão não poderá ser tomado por sua. E, por sinal, nenhum tribunal pode com justiça se arrogar o direito de decidir quais necessidades devam ser incrementadas e satisfeitas. Qualquer tribunal do gênero é repreensível, embora a nossa revulsão não elimine a questão: como podem as pessoas que tenham sido objeto de dominação eficaz e produtiva criar elas próprias as condições de liberdade? (MARCUSE, 1973, p. 27).

De acordo com o excerto, a repressão e os precondicionamentos tendem a eliminar a liberdade dos indivíduos com formas agressivas de doutrinamento e não cabe julgar quais necessidades devem ser satisfeitas, mas incisivamente denunciar a ideologia que está por trás desse fenômeno, tendo em vista que "quanto mais racional, produtiva, técnica e total se torna a administração repressiva da sociedade, tanto mais inimagináveis se tornam os modos e os meios pelos quais os indivíduos administrados poderão romper sua servidão e conquistar sua própria libertação" (MARCUSE, 1973, p. 28). Toda libertação depende da consciência de servidão e o surgimento dessa consciência é sempre obstaculizado pela predominância de falsas necessidades e satisfações que se tornam, em grande proporção, do próprio indivíduo. Portanto, a satisfação dos interesses individuais, longe de significar a expressão da liberdade, representa, na verdade, a perpetuação das relações de produção e consumo precondicionadas.

A mais eficaz forma de guerra contra a liberdade é a implantação de necessidades falsas que perpetuam formas obsoletas de luta pela existência. E pouco importa se a satisfação dessas necessidades é conseguida em um sistema totalitário ou não-totalitário, já que numa sociedade com padrão de vida crescente a crítica e o inconformismo são socialmente inúteis.

À medida que o capitalismo e a tecnologia foram se desenvolvendo, a sociedade industrial avançada foi exigindo um ajuste cada vez maior ao aparato econômico e social, além da submissão à crescente dominação e administração totais. Desta forma, uma "mecânica do conformismo" se espalhou pela sociedade (KELLNER, 1999, p. 26).

A intensidade, a satisfação e até o caráter das necessidades humanas, para além do nível biológico $^{5}$, sempre foram precondicionadas e destinadas a promover a mecânica do conformismo. Trata-se de falsas necessidades, cujo desenvolvimento e satisfação são heterônomos, já que o seu conteúdo e função social são determinados por forças externas que o indivíduo não tem controle algum.

\footnotetext{
5 “As únicas necessidades que tem direito indiscutível à satisfação são as necessidades vitais - de alimento, roupa e teto ao nível alcançável de cultura. $\mathrm{O}$ atendimento a essas necessidades é o requisito para a realização de todas as necessidades, tanto das sublimadas como das não-sublimadas” (MARCUSE, 1975, p. 27).
}

\begin{tabular}{|l|c|c|c|c|}
\hline Govista Dialectus & Ano 8 & n. 14 & Janeiro - Julho 2019 & p. 91 - 109 \\
\hline
\end{tabular}


Grande parte das necessidades comuns padronizadas de diversão, descanso, comportamento, consumo, etc., pertencem à categoria de falsas necessidades e perpetuam a labuta, a agressividade, a miséria e a injustiça. São falsas justamente porque escamoteiam a ideologia do sistema a partir da falsa consciência.

As necessidades humanas estão em estreita relação com o desenvolvimento das forças produtivas e das condições históricas objetivas, porém deveria envolver "padrões que se referem ao desenvolvimento ótimo do indivíduo, de todos os indivíduos, sob a ótima utilização dos recursos materiais e intelectuais à disposição do homem” (MARCUSE, 1973, p. 27). E não é o que se observa no atual estágio de desenvolvimento do capital, uma vez que não houve a suavização da luta pela existência; da mesma forma, a miséria dos indivíduos em diferentes partes do planeta, bem como a satisfação de suas necessidades vitais não são atendidas. Então, não são padrões universalmente válidos, pois decorre da falsa consciência em face da ideologia das sociedades capitalistas, cuja perspectiva política é dominar para se reproduzir sem que haja oposição. A saída apontada por Marcuse está na restituição da razão crítica, que é capaz de libertar a consciência dominada. Sobre a consciência ele diz o seguinte:

O homem tem de vê-la e passar da consciência falsa para a verdadeira, do interesse imediato para o interesse real. Só poderá fazê-lo se viver com a necessidade de modificar o seu estilo de vida, de negar o positivo, de recusar. É precisamente essa necessidade que a sociedade estabelecida consegue reprimir com a intensidade com que é capaz de "entregar as mercadorias" em escala cada vez maior, usando a conquista científica da natureza para conquistar o homem cientificamente (MARCUSE, 1973, p. 17).

Eis o problema, as sociedades capitalistas contemporâneas se mostram capazes de conter a transformação social qualitativa e de estabelecer instituições sociais diferentes a partir de outras concepções de existência humana (que poderiam promover um novo direcionamento nos processos produtivos) pela conquista científica dos indivíduos e da natureza. Tal conquista leva a supressão da crítica e apazigua os antagonistas sociais, estabelecendo um falso consenso que refuta toda a oposição por meio de um sistema tecnológico de dominação e coordenação social. "Essa contenção da transformação é, talvez, a mais singular realização da sociedade industrial desenvolvida" (MARCUSE, 1973, p. 16).

Nesse contexto, a Teoria Crítica enfrenta o seu principal problema, a saber, que a crítica negativa não faz sentido e beira a especulação diante da ideia de transformação social. E, para a Teoria Crítica a negatividade possui um papel fundamental como crítica e forma de evidenciar as contradições para acelerar o movimento das transformações sociais. No caso, a tensão que

\begin{tabular}{|c|c|c|c|c|}
\cline { 2 - 4 } Q Q Onialectus & Ano 8 & n. 14 & Janeiro - Julho 2019 & p. $91-109$ \\
\hline
\end{tabular}


observa está na exclusão da contradição entre o positivo e o negativo em prol de um falso consenso que só fortalece a unidimensionalidade.

Diante desse quadro, o papel da Teoria Crítica é apontar as possíveis alternativas históricas para transformação qualitativa da sociedade. Ela "[...] analisa a sociedade à luz de suas aptidões utilizadas e não-utilizadas ou malbaratadas para aprimorar a condição humana" (MARCUSE, 1973, p. 14). Em última instância, pretende compreender dialeticamente as várias maneiras possíveis e reais de organizar os recursos materiais e intelectuais com ótimo desenvolvimento e possibilidade de suavizar a luta pela existência. Para tanto, avalia os valores que alicerçam as diferentes propostas de organização social para mostrar: 1) se na organização social vigente a vida humana possui dignidade e vale a pena ser vivida; 2) se nela é possível melhorar a vida e se há meios específicos para realizá-la. Cabe analisar se a organização social dispõe de meios para minimizar a labuta pela existência, fazendo uso dos recursos materiais e intelectuais para otimizar a satisfação das necessidades básicas humanas e o desenvolvimento pleno das faculdades individuais.

É o que se investiga nesse artigo, não com a pretensão de apresentar respostas aos problemas emergentes nas sociedades capitalistas, mas de produzir alguma síntese das contradições do nosso tempo com base na racionalidade que permeia as relações humanas. Os pressupostos que Marcuse apresenta acerca da racionalidade tecnológica continuam atuais: não há como desprezar a ideologia capitalista e as contradições sociais que ela produz como o motor da história da humanidade. Além das contradições sociais, na seção seguinte, evidenciou-se a contradição entre a liberdade e a servidão - pensada a partir do pensamento freudiano -, com o intuito de compreender os aspectos psicológicos que fundamentam a dominação da subjetividade.

\section{A compatibilização teórica entre marxismo-freudismo}

O filósofo Herbert Marcuse se destacou como importante teórico do Instituto de Pesquisa Social, filiado à Universidade de Frankfurt. Ele contribuiu para a construção e consolidação de uma teoria social, que ficou conhecida como Teoria Crítica da Sociedade. Em artigo intitulado Filosofia e Teoria Crítica, publicado originalmente em 1937, como parte da elaboração do projeto teórico do Instituto de Pesquisa Social, Marcuse apontou alguns

\begin{tabular}{|c|c|c|c|c|}
\cline { 2 - 4 } & Ano 8 & n. 14 & Janeiro - Julho 2019 & p. $91-109$ \\
\hline
\end{tabular}


direcionamentos metodológicos que são próprios da Teoria Crítica e que o acompanhou ao longo de seus escritos:

[...] a Teoria Crítica da Sociedade está essencialmente vinculada ao materialismo. [...] Há sobretudo dois momentos que vinculam o materialismo à correta teoria da sociedade: a preocupação em torno da felicidade dos homens, e a convicção de que esta felicidade seja conseguida somente mediante uma transformação das relações materiais da existência (MARCUSE, 1997, p. 138).

O autor, como se nota pelo excerto, não faz concessões para o capital, ou seja, para haver transformações sociais qualitativas tem de haver mudanças na estrutura e nas relações materiais de existência. O sistema capitalista tem de esgotar as suas possibilidades e dar lugar a novas formas de existência e os estudos interdisciplinares propostos pelos frankfurtianos pode ser um caminho para vislumbrar possibilidades.

Quando Horkheimer assumiu a diretoria do Instituto de Pesquisa Social, em 1930, propôs um programa de trabalho que enfatizava, sobretudo, a interdisciplinaridade. A Teoria Crítica como fruto da compatibilização entre o pensamento marxista e o freudiano se apresentou como a grande novidade naquele período e abriu espaço para pensar um projeto denominado "materialismo interdisciplinar", que aglutinou em torno do Instituto de Pesquisa Social intelectuais de diversas áreas do conhecimento congregados em um trabalho conjunto de pesquisa como Herbert Marcuse, Max Horkheimer, Erich Fromm, Theodor Adorno, Walter Benjamin, dentre outros (MUSSE, 1997). "Nestes termos, uma das principais tarefas consistia numa adequada refundamentação do pensamento dialético-materialista: eis o eixo da atividade de investigação teórico-filosófica que caberia a Marcuse no ambiente frankfurtiano" (MAAR, 1997, p. 15).

A permanência e a estabilidade do capitalismo foi o que justificou a inclusão da teoria freudiana, entre outros saberes na elaboração conceitual da Teoria Crítica da Sociedade. A finalidade dessa compatibilização feita pelo materialismo interdisciplinar era possibilitar uma compreensão mais abrangente dos aspectos que mantinham a reprodução do sistema capitalista. Nesse sentido, a principal justificativa para o "marxismo-freudismo" se deu, principalmente, pelo fato dos aspectos psicológicos serem decisivos para compreender como um regime repressivo pode ser sustentado pelos oprimidos que vivem nele.

A questão do momento estático do capitalismo, isto é, do seu movimento de reprodução, veio à tona com bastante ênfase, justificando a necessidade, para além dos aspectos econômicos, de

\begin{tabular}{|c|c|c|c|c|}
\cline { 2 - 4 } & Ano 8 & n. 14 & Janeiro - Julho 2019 & p. $91-109$ \\
\hline
\end{tabular}


compreender os demais fatores, sobretudo os psicológicos, atuantes na permanência de um regime que beneficia apenas uma minoria (MUSSE, 1997, s/p).

Havia um pressuposto fundamental a ser compreendido, que era o fato da luta pela permanência e estabilidade do capital não estar sendo travada somente nas esferas política e econômica, mas sobretudo na esfera cultural.

Em livro intitulado O futuro de uma ilusão, Freud (1996) revelou a relação entre os fatores econômicos e os fatores psicológicos que contribuiu para o entendimento do porque a classe trabalhadora renunciou ao seu destino histórico de revolucionar a ordem vigente (FREITAG, 1988). Da mesma forma, a confluência entre marxismo e freudismo permitiu justificar como os indivíduos estão sendo recompensados pelos seus sacrifícios (trabalho) para sublimar a repressão. Marcuse aponta que a introjeção dos valores sociais vigentes na sociedade industrial foi fundamental para consolidar a racionalidade tecnológica.

A recompensa pelos sacrifícios está sugestivamente associada à troca da liberdade pelo conforto. Ou seja, houve a promoção de um conformismo geral pela falsa promessa de felicidade e de bem-estar social em estreita relação com a cultura do consumo.

A situação é delicada. Os consumidores são, afinal, portadores de uma nova exigência de felicidade. No mercado, para onde os conduzem seus desejos, estão condenados a se frustrarem, já que poucos - pouquíssimos! - dispõem de poder de compra suficiente para adquirirem o que supõem que deverá fazê-los felizes. (KONDER, 1998, p. 19).

Essa é a lógica perversa do sistema introjetada pelos indivíduos que, em grande medida, ainda representa, hoje, um problema na luta por emancipação, porque a promessa de felicidade não se cumpre para todos, mas para uma pequena parcela da população. A despeito disso, "uma falta de liberdade confortável, suave, razoável e democrática prevalece na civilização industrial desenvolvida, um testemunho de progresso técnico" (MARCUSE, 1973, p. 23).

Os indivíduos não somente se adaptaram a um padrão de vida crescente marcado pela fluidez na distribuição de mercadorias, mas se tornaram veículos de uma cultura. "O que principiou como submissão pela força cedo se converteu em servidão voluntária, colaboração em reproduzir uma sociedade que tornou a servidão cada vez mais compensadora e agradável ao paladar" (MARCUSE, 1975, p. 15). A contradição entre liberdade e servidão foi naturalizada e se tornou um veículo do progresso.

O pensamento freudiano, nesse aspecto, foi fundamental para interpretar as sociedades industriais, pois mostram a existência de um aspecto sociopsicológico que interfere na condição

\begin{tabular}{|c|c|c|c|c|}
\cline { 2 - 4 } Q Q Onialectus & Ano 8 & n. 14 & Janeiro - Julho 2019 & p. $91-109$ \\
\hline
\end{tabular}


política, - os indivíduos introjetam a ideologia dominante e reproduzem os controles externos exercidos pela sociedade capitalista. É fato, portanto, que o precondicionamento da subjetividade garante a reprodução do capital, isto é, ao lutar pela a existência os indivíduos reproduzem o sistema.

No livro Eros e Civilização: uma interpretação filosófica do pensamento de Freud, publicado em 1955, Marcuse emprega categorias freudianas para explicar como as condições psicológicas se converterem em condições políticas para a reprodução do capital.

\begin{abstract}
O homem animal converte-se em ser humano somente através de uma transformação fundamental da sua natureza, afetando não só os anseios instintivos, mas também os 'valores instintivos' - isto é - os princípios que governam a consecução dos anseios [...] Freud descreveu essa mudança como a transformação do princípio de prazer em princípio de realidade (MARCUSE, 1975, p. 34). Grifos do autor.
\end{abstract}

Essa passagem do princípio de prazer para o princípio de realidade - da ordem instintiva para a ordem racional - foi um acontecimento traumático no desenvolvimento do homem em sua individualidade (ontogeneticamente) e na coletividade (filogeneticamente). O princípio de realidade materializa-se em um sistema de instituições e o indivíduo inserido nesse sistema apreende os requisitos desse princípio, ou seja, a lei e a ordem, transmitindo-os às gerações seguintes. Com o estabelecimento do princípio de realidade o ser humano suprimiu o princípio de prazer: o que outrora era "um feixe de impulsos animais" foi convertido em um ego organizado. Nesse sentido, os indivíduos tornaram-se conscientes e propícios para introjetar uma racionalidade imposta de fora. Trata-se de uma luta contra a liberdade que ocorre na mente do homem, como uma "autorepressão" do indivíduo reprimido. "É essa dinâmica mental que Freud desvenda como a dinâmica da civilização" (MARCUSE, 1975, p. 37).

Para Marcuse (1975), um dos motivos da sociedade impor a modificação da estrutura instintiva é econômico, até porque ela não tem meios suficientes para sustentar a vida de seus membros sem o trabalho deles, porém "a livre gratificação das necessidades instintivas do homem é incompatível com a sociedade civilizada" (MARCUSE, 1975, p. 26). Dessa forma, nas sociedades capitalistas está previsto o desvio das energias das atividades sexuais dos indivíduos para o trabalho alienado.

O trabalho tornou-se agora geral, assim como as restrições impostas à libido: o tempo de trabalho, que ocupa a maior parte do tempo de vida de um indivíduo, é um tempo penoso, visto que o trabalho alienado significa ausência de gratificação, negação do princípio de prazer. A libido é desviada para desempenhos socialmente úteis, em que o indivíduo trabalha para si mesmo somente na medida em que trabalha para o sistema, empenhado em atividades que, na

\begin{tabular}{|c|c|c|c|c|}
\cline { 2 - 4 } Q Revista Dialectus & Ano 8 & n. 14 & Janeiro - Julho 2019 & p. $91-109$ \\
\hline
\end{tabular}


grande maioria dos casos, não coincidem com suas próprias faculdades e desejos (MARCUSE, 1975, p. 58).

De um ponto de vista psicológico, o processo de repressão internalizado pelo superego permitiu o processo civilizatório, mas, de um ponto de vista político, Marcuse mostra que a sociedade industrial conquistou os homens cientificamente, isto é, os homens reproduzem a eficiência do aparato tecnológico e vivem sob a constante repressão e mais-repressão para mantê-lo, consumindo mercadorias. A repressão produz modificações nos instintos necessários à perpetuação do processo civilizatório e a mais-repressão, por sua vez, designa as restrições requeridas pela dominação social contemporânea, distinguindo-se, portanto, da repressão. Foi preciso introjetar nos indivíduos os valores da cultura do consumo para implantar gradualmente um processo de administração total da vida. Isso porque o fenômeno da reprodução e perpetuação dos controles externos depende da internalização da repressão.

A administração científica das necessidades instintivas converteu-se, desde há muito, em fator vital na reprodução do sistema: a mercadoria que tem de ser comprada e usada traduz-se em objetos da libido [...] o povo, eficientemente manipulado e organizado, é livre; a ignorância e a impotência, a heteronomia introjetada, é o preço de sua liberdade. (MARCUSE, 1975, p. 14).

Percebe-se que a ideologia da sociedade industrial explorou e dominou a consciência do indivíduo por meio de processos de introjeção, reduziu e alterou a condição de um potencial opositor ao sistema a veículo de sua cultura.

Dessa forma, ideia de liberdade interior ganhou outra conotação sob os ditames repressivos da ideologia da sociedade industrial, tornando-se um poderoso instrumento de dominação. A escolha não é mais um parâmetro para determinar o grau de liberdade, mas o que pode ser escolhido entre uma ampla variedade de mercadorias e serviços que sustêm pleno controle sobre a vida. As necessidades superimpostas pelo sistema de produção testemunham a eficácia da internalização da repressão, inserindo um hábito de busca incessante por satisfação, que é por si mesmo, uma forma de compensação.

\section{Considerações finais}

A ideologia da sociedade industrial explorou o indivíduo naquilo que é especificamente seu: a consciência. Por meio de processos de introjeção transformou e moldou os indivíduos para a servidão voluntária, isto é, para se reproduzir enquanto a luta pela existência se

\begin{tabular}{|c|c|c|c|c|}
\cline { 2 - 4 } Q Q Onialectus & Ano 8 & n. 14 & Janeiro - Julho 2019 & p. $91-109$ \\
\hline
\end{tabular}


materializa no trabalho alienado em função dos interesses capitalistas. A mecânica do conformismo tem suprimido as possibilidades de oposição ao sistema e as perspectivas alternativas de organização social.

Nota-se que a unidimensionalidade fortaleceu o falso consenso e escondeu as contradições sociais. A troca da liberdade pelo conforto se tornou uma promessa de felicidade que se concretiza para poucos, mas tem servido aos propósitos da compensação e da sublimação para todos os indivíduos, a despeito da administração total da vida por meio da repressão e da mais repressão ter progressivamente se intensificado.

Em vista do exposto, a transformação social qualitativa depende da consciência da servidão e, a restituição da razão crítica é tarefa para Teoria Crítica realizar todos os dias, a fim de minimizar os impactos da mecânica do conformismo e para manter vivo o espírito de resistência, de recusa, de insubordinação de insubmissão ao sistema que explora a subjetividade e inviabiliza a passagem do reino da necessidade ao reino da liberdade. A luta, agora, é para transformar o nosso estilo de vida condicionado, de negar o positivo, de recusar! Diante do poder ideológico e da totalidade repressiva das sociedades capitalistas, evidenciar para negar continua a ser o passo fundamental para qualquer transformação social qualitativa.

Até o momento, observou-se que as sociedades capitalistas não minimizam a luta pela existência e nem utilizam os recursos materiais e intelectuais para melhorar a vida de todos os indivíduos, mas apenas de poucos que conseguem satisfazer plenamente suas pulsões. No atual estágio de desenvolvimento das forças produtivas, a revolução tecnológica tem produzido mais exclusão do mercado de trabalho do que proporcionado meios de luta justa pela existência de todos os indivíduos. No planeta, as economias que representam as periferias do capital não têm expectativas nem de inserção e nem de crescimento por meio do trabalho, senão os países ditos emergentes que estão na vanguarda da economia dependente com a nobre missão de produzir commodities (como é o caso do Brasil) para os países ricos e detentores dos meios de dominação - detentores dos meios necessários para a produção tecnológica.

Possivelmente, teremos de repensar a ideia de um exército de reserva e entender que as formas de exclusão do trabalho geram um exército de miseráveis sem expectativa, em meio à riqueza e desenvolvimento produzidos pela reestruturação produtiva com base na racionalidade tecnológica e no pensamento neoliberal encabeçado pelos organismos internacionais, como o Banco Mundial, o Fundo Monetário Internacional, Organização Mundial do Comércio, dentre outros.

\begin{tabular}{|c|c|c|c|c|}
\cline { 2 - 4 } Q Devista & Ano 8 & n. 14 & Janeiro - Julho 2019 & p. $91-109$ \\
\hline
\end{tabular}


Essa perspectiva representa a grande tensão do nosso tempo. A contradição que precisa ser pensada e repensada a fim de que se produzam sínteses a guisa de possíveis caminhos para a superação do capital, que já tem dado mostras de esgotamento das possibilidades civilizatórias. Problemas de todas as ordens explodem em todas as partes do mundo ambientais, sociais, culturais, políticos, religiosos. Serão problemas insolúveis?

\section{Referências:}

CHAUI, M. Manifestações ideológicas do autoritarismo brasileiro. Organizador André Rocha. Belo Horizonte/MG: Autêntica; São Paulo: Editora Fundação Perseu Abramo, 2013.

FREITAG, B. A Teoria Crítica: ontem e hoje. 2. ed. São Paulo: Brasiliense, 1988.

FREUD, S. O futuro de uma ilusão; O mal-estar na civilização e outros trabalhos (1927 1931). Edição Standard brasileira das obras psicológicas completas de Sigmund Freud. Vol. XXI. Rio de Janeiro: Imago, 1996.

KELLNER, D. Introdução. Tecnologia, guerra e fascismo: Marcuse nos anos 40. In: KELLNER, D. (editor). Tecnologia, guerra e fascismo: coletânea de artigos de Herbert Marcuse. São Paulo: UNESP, 1999.

On Marcuse: critique, liberation, and reschooling in the radical pedagogy of Herbert Marcuse. Sobre Marcuse: crítica, libertação e reeducação na pedagogia radical de Herbert Marcuse. In.: Revista Estudos e Pesquisas em Psicologia [online]. Vol.11, n . 1, 2011, p. 2355. http://pepsic.bvsalud.org/pdf/epp/v11n1/v11n1a03.pdf. Acessado em 10/10/2018

KONDER, L. O que é dialética. São Paulo: Brasiliense, 2006. p. $15-28$.

Marcuse, revolucionário. In.: Physis: Rev. saúde coletiva. 8(1). Rio de Janeiro, 1998,

MAAR, W. L. Marcuse: em busca de uma ética materialista. In: MARCUSE, H. Cultura e Sociedade. Vol. I. 1. ed. São Paulo: Paz e Terra, 1997.

MARCUSE, H. A ideologia da sociedade industrial: o homem unidimensional. 4. ed. Rio de Janeiro: Zahar, 1973.

Eros e Civilização: uma interpretação filosófica do pensamento de Freud. 6. ed. Rio de Janeiro: Zahar, 1975.

Filosofia e Teoria Crítica. In: MARCUSE, H. Cultura e Sociedade. Vol. I. 1. ed. São Paulo: Paz e Terra, 1997.

\begin{tabular}{|l|c|c|c|c|}
\cline { 2 - 4 } & Ano 8 & n. 14 & Janeiro - Julho 2019 & p. $91-109$ \\
\hline
\end{tabular}


Algumas implicações sociais da tecnologia moderna. In: KELLNER, D. (editor). Tecnologia, guerra e fascismo: coletânea de artigos de Herbert Marcuse. São Paulo: UNESP, 1999.

MUSSE. R. As raízes marxistas da Escola de Frankfurt. Conferência proferida em 14 de julho de 1997, na abertura do Curso de Extensão sobre a Escola de Frankfurt para o Curso de Direito, na Faculdade de Direito da UFPR. Disponível em: http://webcache.googleusercontent.com. Acessado em 11/01/16.

\begin{tabular}{|l|c|c|c|c|}
\cline { 2 - 4 } Q Q Dialectus & Ano 8 & n. 14 & Janeiro - Julho 2019 & p. 91 - 109 \\
\hline
\end{tabular}

